\title{
1959-1968: The Formative Years
}

\author{
Georg Fràter*
}

\begin{abstract}
The author describes his time at the University of Zurich from his undergraduate days attending courses by Professors Schmid, Clusius and Schumacher culminating in the dreaded house exams to graduate and postgraduate research supervised by Hans Schmid.
\end{abstract}

Keywords: Institute of Organic Chemistry UZH

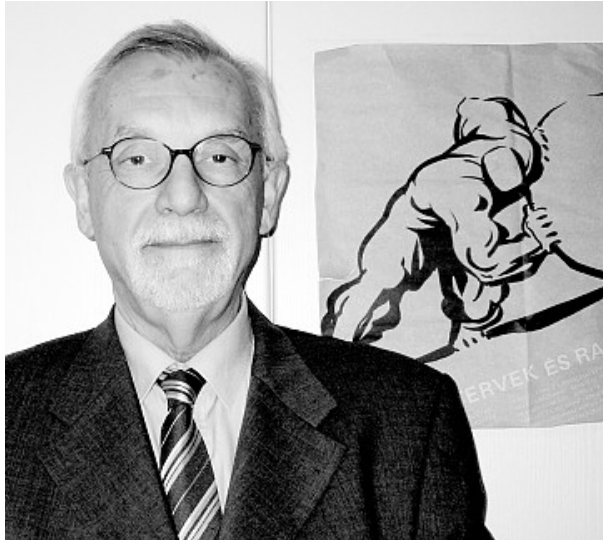

Georg Fràter
In 1959 after obtaining the final leaving certificate of a Swiss gymnasium (kantonale Maturität), I enrolled at the University of Zurich, with the goal to study chemistry. In spite of lacking a clear concept, I had known for a long time that I wanted to study chemistry.

My father, a mechanical engineer, had a friend, Dr. Béla Dorner (born 1881, graduated 1905 in Budapest), who was a chemist. In the late 40s they worked on a project to manufacture paper from corncob residues. The test procedure was successful and a pilot plant was set up in a Hungarian paper factory in Füzfö.

Dr. Dorner was the first chemist in my life and I remember him well. In the first year of the Budapest gymnasium we had our very first chemistry lessons. These lessons appear rather hazy in my memory, but apparently they had not disheartened me from my goal to study chemistry, contrary to my classmates, most of whom developed a lifelong aversion or at least disinterest toward chemistry.

The second year in this gymnasium was interrupted by the Hungarian revolution in the autumn of 1956. I left Hungary as a refugee and half a year later I was enrolled in the Institute Juventus on the Lagerstrasse in Zürich to prepare myself for the final certificate. This private school was paid by an anonymous benefactor to whom I am ever grateful.

Dr. Samodunski gave us chemistry classes. We had not only theory, but extensive laboratory practice as well. This period confirmed my decision, by providing a notion about chemistry, which later turned out to be correct. Chemistry is a wonderful mixture of strict rules, with balanced exceptions, ruled by empirical data, yet driven by improvisation and fantasy. This concept matured during my time at the Rämistrasse, under the guidance of great teachers, leading me to a greater understanding of chem- istry and ending in my development of a great life long passion.

The chemistry study program at the University of Zürich appeared rather confusing to the freshly enrolled student, to say the least, and could even be termed as chaotic. From today's angle, with or without Bologna, where every student studies according to a strict regime, those distant years appear slightly medieval. This can also be seen in a positive sense. The positive aspects are related to freedom of choice and being solely responsible. What I/we did not realise in this period is, that the whole institute was in a turmoil, in a state of reorganisation from one single chemistry institute to three in one, inorganic, organic and physical chemistry. Precisely in the winter semester of 1959/1960 Professor Karrer had retired after many years of directorship. We met him, now and then, in the corridor, the small and great man, the Nobel laureate. We greeted him with great respect and he lifted his hat, politely but slightly absentmindedly. An era had quietly passed by.

I cannot remember a clear study plan that we had to conform to, but I well remember one or two visits with Professor Schumacher, who was the Director of Inorganic Chemistry at the time, to ask him which practical classes and lectures he could recommend, and in which order. His advice was presented with much patience, as well as knowledge and apparently I was not the only one to have received his useful directions. It was also his influence that convinced the biology student, Miss Marijke Schröder, to change her major topic after the first study year, from biology to chemistry. Five years later Marijke and I were married and are still happily so. She later wrote a doctoral thesis on natural products with Professor Viscontini. We both acknowledge and thank Professor Schumacher for his guidance in the early years. 
I believe that nobody from our study year finished with a diploma, if it were possible at all. I think from 1965 on some made a diploma work before the $\mathrm{PhD}$. The preferred route was the direct route to obtain the PhD. Even a pre-diploma or the equivalent bachelor degree was unknown at the time. However it was still necessary to test the scientific progress of the chemistry students and therefore the feared so-called 'house exams' were introduced in the inorganic, physical and organic chemistry study routes.

The 'house exams' were an archaic institution, possibly from Professor Karrer's period. These exams were held with only the student and the professor present and were without a time limit, i.e. they lasted from one to five hours (long exams more frequently occurred with Professor Schmid). If you failed, this could be repeated, as the examiners, Professors Schmid, Clusius and Schumacher, thought fit. Each student could report to the relevant professor and could register for this exam, when he or she had the feeling that one could dare to go in. The result was either success or failure and there was no paper to document this for the student.

The 'Fortgeschrittenpraktikum' was an instrumental organic chemistry practical class for advanced students. This 'Praktikum' was extraordinarily well organized by Professor Eugster and was a very useful prerequisite for the start of a doctoral work.

The graduate student 'seminars' were in those times on Saturdays at 10 o'clock. Frequently the graduate students had to present and discuss a topic of general interest before colleagues and professors. This was the first obligatory presentation. Later on we had to present our own PhD topic in a second seminar. I remember that we had once a visitor from the neighbouring ETH, Professor Eschenmoser, on a certain Saturday, making the comment, "this seminar at the university is the only place in Zürich, where it is possible to listen to chemistry on a Saturday".

The Rämistrasse 76 became my home, especially during the dissertation and the subsequent post-doc period. I was very lucky, because when I started my thesis, I was able to join Dr. Richard Barner in his laboratory No. 14, a small laboratory for two persons. On the one hand Dr. Barner taught me many tricks and manipulations in the lab, on the other hand he also supported me, during our weekly session with the 'boss' (der Alte). 'Der Alte' was the common name for Professor Schmid, given to him by his co-workers and students how could it be otherwise. These meetings turned out to be a school for life. At the beginning one was fearful and stressed - with eager anticipation of what was to come. It

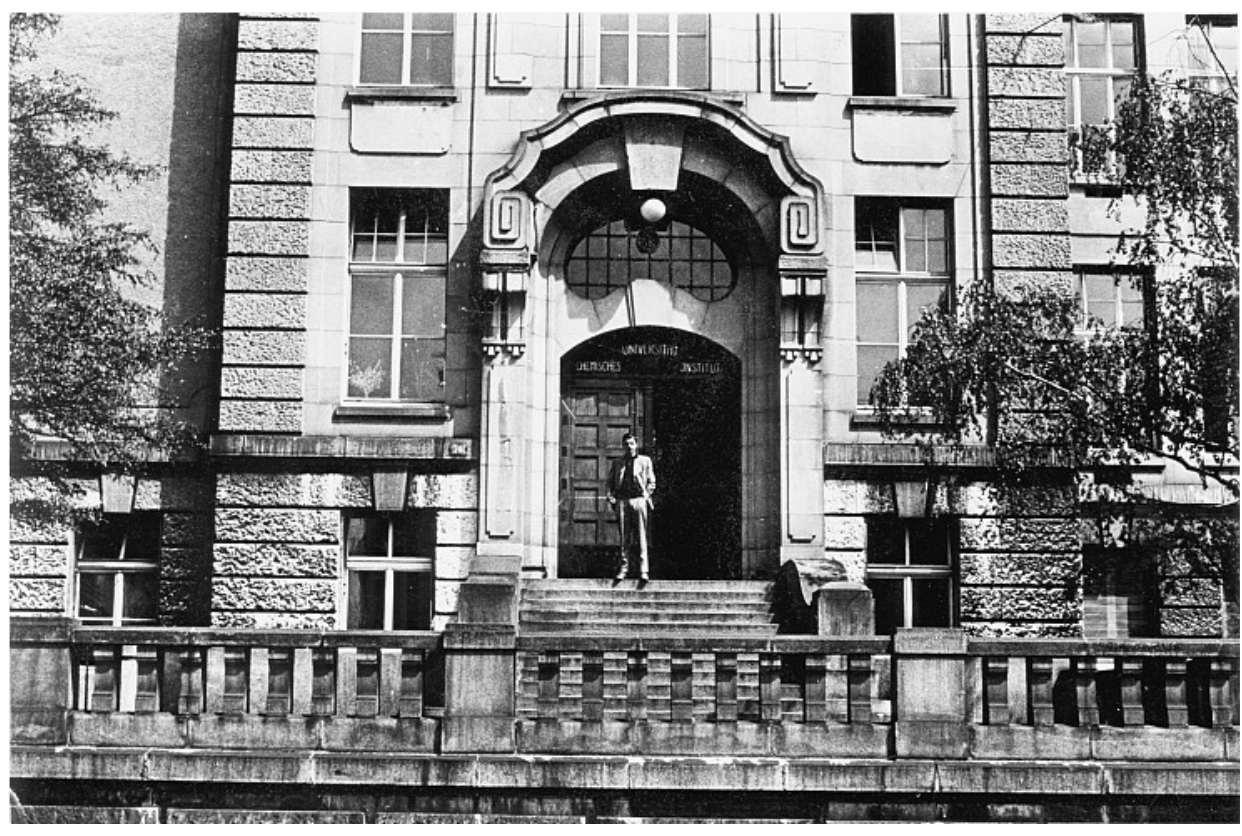

Rämistrasse 76, 1967: 'Me and the institute', the right order at that time

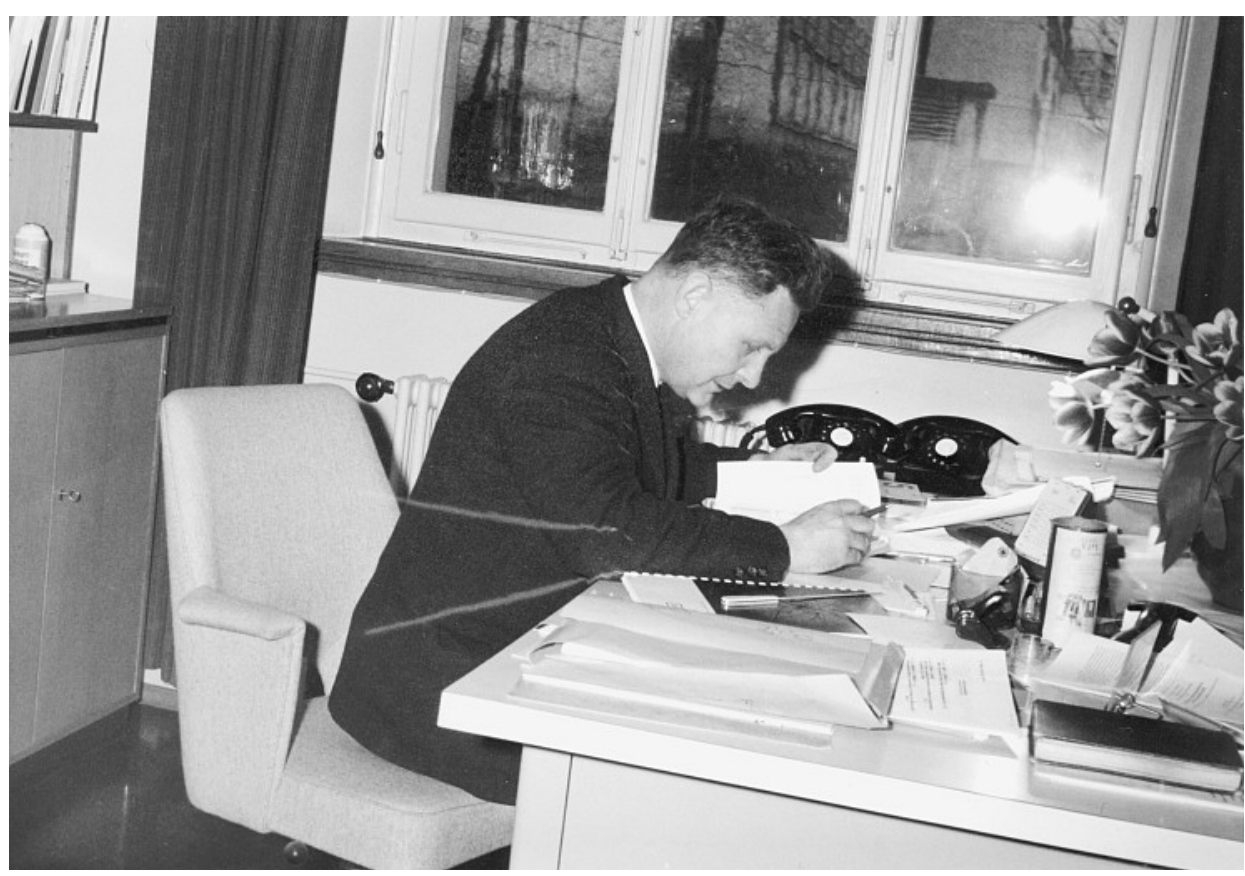

Professor Schmid, the boss, at his desk in the Institute of Organic Chemistry

was easy to enrage the boss by general chatter, with imprecise facts, with fuzzy observations or with over interpretations. He had a tendency to fits of rage, a choleric temper. I had to submit to several such smaller and larger outbursts. However, he was able to drive me/us to extreme achievements. Today it would be termed motivation. As a result we were good, diligent, enthusiastic and worked long hours with pleasure. We were proud of ourselves, of our boss and of the institute.

Professor Schmid was no great administrator, but he was curious concerning our results and with interesting new results/data in hand, one could disturb him at any time of the day. He controlled everything. NMR spectroscopy was in its beginnings and Professor Schmid learned the new technique together with us. He measured out every coupling constant by himself, with a magnifying glass. Detailed IR and UV spectra had to be presented to him. GC peaks were quantified with a planimeter.

We learned to think of and perform the proper control reactions, and we performed as many as were necessary, and many more, until he was satisfied and could believe them. I still have his slightly ironic but not unfriendly tone in my ears, saying: "Well, we will now listen to Mr Fràter, and how he thinks that he has proved a $[5,5]$ sigmatropic rearrangement". Discipline, hard working, a critical mind and skepticism, a tough 


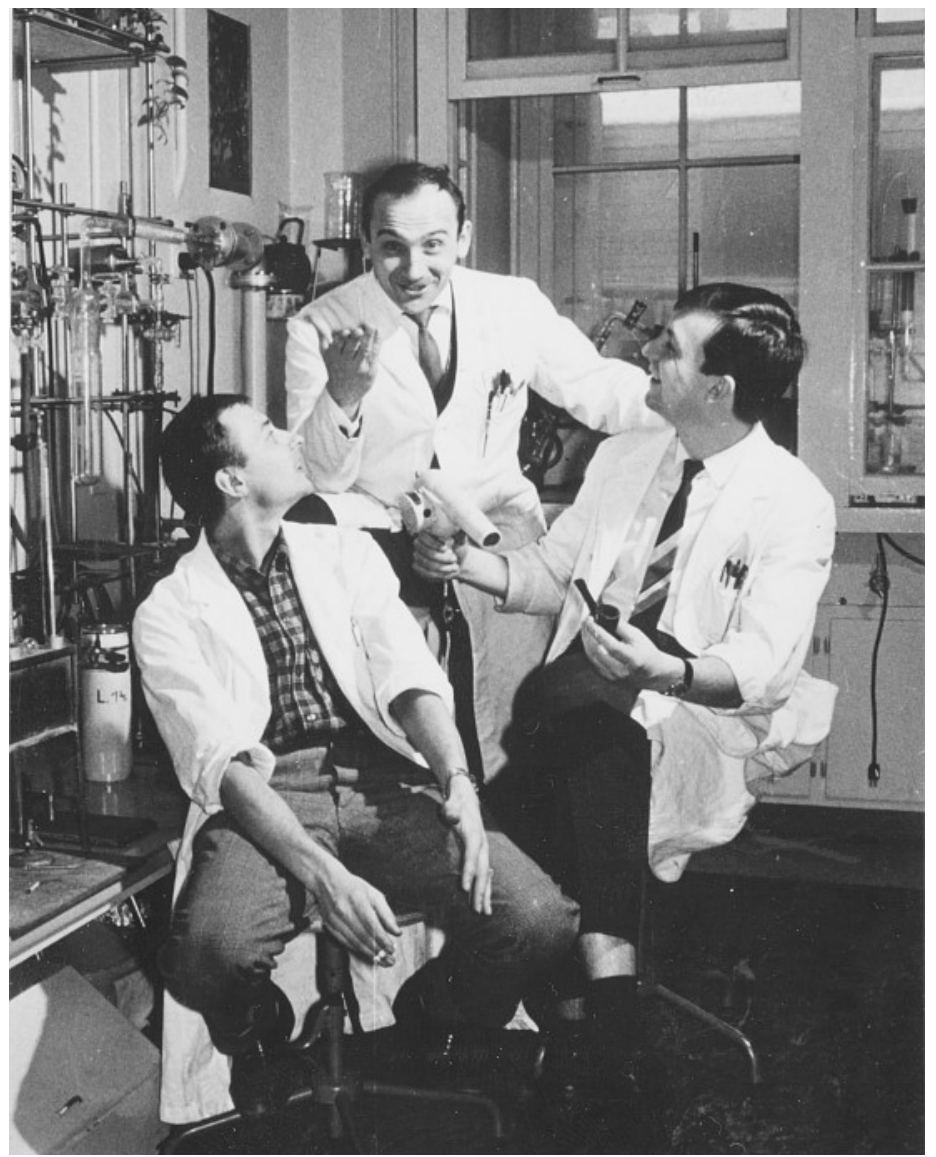

In laboratory No. 14 on February 4, 1965. We are fooling around. From left to right: Jànos Zsindely; Ferenc Sàgi, a postdoc fellow with Professor Viscontini, who is mayor of Ontex in France, today; Georg Fràter

education, but after this education there were no big surprises in real life.

I recollect certain lectures/classes. Professor Clusius lectured physical chemistry. For me he was the Grand Seigneur in the institute. His lectures were exemplary. The organic chemistry lecture 'Mechanistic Organic Chemistry' from Professor Schmid is still stored in my cupboard at home. This is no printed manuscript, that was not yet en vogue, it consists of my own handwritten notes. The class, 'Stereochemistry of Organic Molecules', from Professor Dreiding also guided me as my interests developed. Important for the operative functions in the institute on the Rämistrasse, were the Hochstrassers. Herr and Frau Hochstrasser were the housekeepers. Herr Hochstrasser was the totum factum. They lived in an apartment in the institute. They managed the 'material chemistry shop' for chemicals and lab utensils. He also controlled the 'Night Lab', i.e. he looked after everything. Today one would call it facility management and you can even study it. It was to your advantage to be on good terms with the Hochstrassers. If this was not working so well, it could well mean that a doctoral degree might have taken a little longer than usual.

The old institute was in downtown Zürich, not on the outskirts, where it stands today. Behind the institute there was an important social meeting place that could be visited between two lab experiments: the restaurant Plattenhof. In the Plattenhof, Martha was a most important personality. I am certainly not the first to remember motherly Martha in a nostalgic way. She served generations of students with beer. On the Hottingerplatz there was a Frauenverein restaurant with cheap menus and a little further on, in the Klosbachstrasse, a blessed Hungarian confectioner ruled a pastry bakery, Mr. Szöke. We, Marijke, Hans-Jürgen Hansen, Jànos Zsindely, myself and others, walked over there rather frequently to taste and enjoy his unrivalled, magnificent sweet creations.

As I mentioned before, the boss was able to propel us to perform great deeds. Writing publications with Professor Schmid was normally done late after lab work or preferably on Sunday morning. He was our example for 'total emersion' in chemistry and he became a role model, a father figure. It was not surprising with this example before me that I have always given research the highest priority. As a consequence, my administrative duties usually received slightly less attention.

Those nine years at the Institute of Chemistry of the University of Zurich on the Rämistrasse gave me the freedom to think independently, taught me to take full responsibility for my authentic decisions and provided me with a lifelong hobby as well. Passion for the observation of nature, for discovering the new and for attempting daring experiments, combined with a large portion of skepticism, showed me the way to lifelong satisfaction as a scientist. Those were very happy years. I am thankful for them.

Received: January 30, 2008 